\title{
Quantification of Emissions Generated from Domestic Burning Activities from Townships in Johannesburg
}

\author{
Seneca Naidoo *1,3, Stuart J. Piketh ${ }^{2}$, Christopher Curtis ${ }^{3}$ \\ ${ }^{1}$ South African Weather Service, Private Bag X097, Pretoria 0001, South Africa, seneca.naidoo@weathersa.co.za \\ ${ }^{2}$ School of Geo- and Spatial Science, Unit for Environmental Sciences and Management, North-West University, \\ Potchefstroom Campus, Private Bag X6001, Potchefstroom 2520, South Africa, stuart.piketh@nwu.ac.za \\ ${ }^{3}$ School of Geography, Archaeology and Environmental Studies, University of the Witwatersrand, Private Bag 3, \\ Wits 2050, South Africa, Christopher.Curtis@wits.ac.za
}

\begin{abstract}
Domestic burning activities, specifically in informal settlements, contribute greatly to the air quality problems experienced by most developing urban centres. Low-income households that exist within townships in South Africa house a large portion of the South African population. These households burn vast quantities of coal, wood and other substances to provide for their energy needs. Pollutants emitted as a result of domestic burning are estimated to be one of the leading causes of respiratory illnesses in inhabitants of townships. To better understand the relationship that exists between domestic burning and the resultant pollutants, a method of quantifying these pollutants has been developed for a completely un-electrified settlement, near Johannesburg, using the quantities and type of fuel consumed. Seasonality, availability, price and cultural aspects all have a bearing on the fuel source choice and the quantity consumed. The most significant temporal observations identified for domestic burning are seasonal ones.
\end{abstract}

Keywords: Domestic burning, informal settlements, urban air pollution, domestic energy

\section{Introduction}

Domestic burning is an activity that has been exercised for centuries and for a range of functions. There are parts of both the developed and developing world that rely on some sort of domestic burning as a source of energy. Estimates have suggested that carbon emissions generated from domestic fuels is the second largest source of biomass burning, on a global scale, and that Africa contributes significantly to this (Bertschi et al. 2003).

Rapid urbanisation and the related growth of informal settlements have worsened the backlog in the distribution of basic services such as electricity provision. Townships in South Africa are mainly characterised by low-income households, where domestic burning is a common practice (Balmer 2007). Although Gauteng exhibits the smallest surface area when compared to the other 8 provinces, it is the most populated province in South Africa and has also been identified as the wealthiest. For this reason, Gauteng has, in recent years, witnessed increasing levels of mass migration of the poor into large city centres such as Johannesburg and Pretoria. As such, the province of Gauteng has one the highest percentages of people living in informal housing. Although there has been a considerable decrease in the percentage of Gauteng's households living in informal dwellings, from $23.9 \%$ in 2001 to $18.9 \%$ in 2011 , Gauteng still remains the province with the second highest percentage of informal houses, with a total of 739901 informal houses recorded in 2011. According to the most recent census study, the province also has the second highest number of households without access to electricity, at 501029 houses recorded in 2011 (Stats SA August 2013). For this reason, Gauteng contributes largely to the emissions generated from townships in South Africa.
The objectives of this research is to identify the fuel sources most commonly burnt, in the informal settlement of Zenzele, during the winter of 2011 and further quantify the emissions generated from these combustion processes. This research aims to contribute towards the already existing research on a domestic burning emissions inventory for South Africa and clarifying some of the uncertainties that exist within the study area of domestic fuel combustion.

\section{Domestic Burning and Related Effects}

\subsection{Fuel Sources and their Associated Pollutants}

A variety of fuel sources are burnt during domestic burning activities in townships. The two major fuel sources consumed in these areas during winter have been identified as coal and wood, although other substances such as paraffin, liquid petroleum gas (LPG), animal dung and electricity are also utilised to provide for the energy needs of inhabitants of informal settlements (Ludwig et al. 2003). Common fuel sources utilised during the warmer summer months are paraffin, candles, electricity and gas. Gas is also a popular choice for cooking purposes but is often too expensive, in relation to paraffin. Paraffin is the most common source within completely unelectrified settlements, as it is used mainly for cooking but also lighting by means of paraffin lanterns (Muller et al. 2003). Households tend to utilise coal and wood as a result of its multi-functional nature. These fuels can be used for both cooking and lighting functions, as well as, simultaneously, for space heating purposes (Scorgie 2003).

The importance of particulate matter, trace gases and other pollutants associated with domestic burning activities are well recognised as pollutants that have 
an effect on global climate change; and have also been gaining interest in the context of human health. Some of these trace gases include carbon dioxide $\left(\mathrm{CO}_{2}\right)$, carbon monoxide (CO), nitrogen monoxide (NO), methane $\left(\mathrm{CH}_{4}\right)$, nitrous oxide $\left(\mathrm{N}_{2} \mathrm{O}\right)$ and sulphur dioxide $\left(\mathrm{SO}_{2}\right)$, amongst many others (Crutzen et al. 1990). Most of these gases are precursors of other gases and pollutants, and together, all have a significant influence on the chemistry of the atmosphere.

Almost all of the above pollutants emitted as a result of domestic burning activities fall into the category of criteria pollutants. As such, these pollutants have been deemed hazardous and have an impact on both the environment and more specifically on human health. For this reason, the emission of criteria pollutants into the atmosphere is controlled by national ambient air quality standards (Aneja et al. 2001).

\subsection{Climate Effects}

\subsubsection{Atmospheric Chemistry and the Loading Budget}

A host of trace gases, the major greenhouse gases as well as atmospheric aerosols associated with biomass burning and on a lesser scale, domestic burning, have an influence on the globe's atmospheric chemistry and loading budget. Atmospheric aerosols created during domestic burning have an important influence on the earth's radiative budget in that their radiative forcing acts in the opposite direction to greenhouse gases present in the atmosphere (Anderson et al. 1996).

Carbonaceous aerosols too, in the form of soot or black carbon particles possess the ability to absorb visible light, whereas, most other elements of atmospheric aerosols are only capable of scattering this incoming light (Adachi et al. 2008). The high absorption efficiency of black carbon significantly enhances the heating of the atmosphere, further adding to the warming effect, already established by green house gases (Wentzel et al. 2003).

\subsubsection{Atmospheric Transport}

The impact of aerosols, particulate matter and a range of other pollutants on the climate and environment can also be widespread. Some emissions associated with domestic burning activities are often localised and seldom have an effect outside of the immediate area. These pollutants have short residence times and are, therefore, most significant at a local level. For this reason, they are deemed hazardous substances in light of human health.

\subsection{Health Risk Potential}

There are numerous health risks associated with domestic burning activities, which act on the respiratory system, as a result of the inhalation of particulate matter and other emitted pollutants. In developing countries, the burning of coal and biomass contribute largely to a range of pollutants that lead to pulmonary and related respiratory diseases (Boleij et al. 1989). Carbon monoxide poisoning and respiratory illnesses occur as a result of these burning activities, together with poor ventilation, which is a characteristic feature in informal housing (Balmer 2007).

Davis (1998) describes kerosene as a "transitional fuel" that is being made use of more often as a larger percentage of informal settlements become electrified (Davis 1998). Better known as paraffin, this fuel source generates sizeable amounts of a variety of pollutants, which include carbon monoxide, nitrogen dioxide and a host of hydrocarbons and volatile organic compounds (Muller et al. 2003).

\section{Data and Methodology}

\subsection{Study Site Description}

Zenzele is a small informal settlement situated in the south of the Randfontein Local Municipality, in the province of Gauteng, as indicated in figure 1 below. The Randfontein Local Municipality is situated to the south-west of Johannesburg, between the Mogale City and Westonaria local municipalities. It is relatively small in relation to the other two local municipalities but presents high levels of unemployment and poverty. Of the total number of households in Zenzele, $98.7 \%$ are classified as "informal" and $98.8 \%$ of the households do not have access to electricity (RLM 2010).

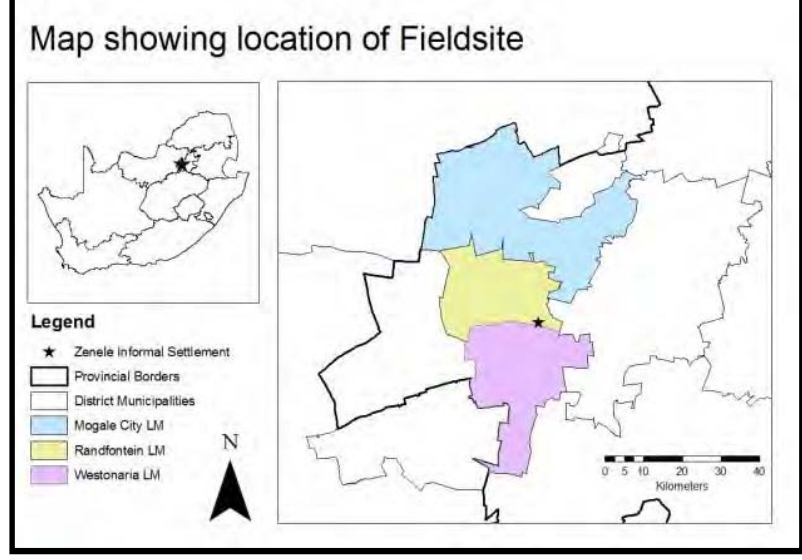

Figure 1. Map showing the location of Zenzele (adapted from Municipal Demarcations Board, municipal data set)

Analysing and reviewing the census data collected and compiled in 2001, allows for an initial assessment of similar data pertaining to informal settlements, such as population density and the provision of basic services. Sieving through this data, further allows for an in-depth look at the province of Gauteng and more specifically the area of study, Zenzele. 
Questionnaires and hanging scales, distributed to a number of randomly selected households within the township, were used to identify and measure the quantities of various fuel sources being burnt. The fuel consumption rates, and the emission factors for these selected fuels and pollutants, allows for the emission to be quantified over that specific area. The questionnaires were designed to gather information on the burning behaviours of residents and the specific types of fuel sources utilised within the area of study which allows for the most dominant fuel source to be identified.

Fifteen informal households in Zenzele were selected to participate in the fieldwork study. Participants were required to weigh the amounts of wood and/or coal they used on a daily basis for both the morning and evening burning sessions. This study was conducted over a 5 month period, from the beginning of May 2011 until the end of September 2011. Data collected after the 5 month period were analysed and emissions were calculated using emission factors presented in the 2004 FRIDGE (Funds for Research into Industrial Development, Growth and Equity) Report. The emission rates of $\mathrm{SO}_{2}, \mathrm{PM}_{10}, \mathrm{CO}_{2}$ and $\mathrm{CO}$ were calculated for coal and wood, using these emission factors.

\section{Domestic Energy Use}

\subsection{Questionnaires}

Feedback from the questionnaires distributed during the study highlighted a number of major seasonal findings, as illustrated in the figure below. Figure 2 presents the percentages of the different fuel sources consumed by the 15 households for cooking, heating and lighting purposes over the various seasons. It was discovered that coal and wood are burnt very infrequently during summer. Within most partially or completely electrified households, where household income was somewhat higher than that in unelectrified households, electricity was the preferred source of energy. Although electricity was relatively more expensive than some of the other fuel sources, some people opted for the convenience that comes with using this fuel source.

The case, however, was a little different for electrified households, in which elderly women reside or those that are run by an elderly head. Families that owned coal stoves that were usually passed down from one generation to the next, preferred to use these stoves during winter when there was a great need for solid fuels that provided more heat. The reasons for this are two-fold: the most obvious one being the multifunctional capabilities of this appliance. Coal stoves are generally used for cooking but also provide large quantities of heat in the process. The second reason is one that is not widely found in the literature as it involves the cultural aspects linked to the combustion of domestic fuels. Mdluli (2007) has carried out extensive research in this field of study, specifically focusing on the cultural aspects associated with the combustion of coal in informal townships. She has explained that within townships, coal burning instils a sense of family and community amongst residents (Mdluli 2007).

Informal homes, however, that do not have access to this basic service, choose gas or paraffin as their preferred fuel sources for cooking and lighting during summer. The amount of fuel required for heating during this summer period is not significant enough to warrant a mention as the residual heat produced from cooking is sufficient to keep homes warm during summer.

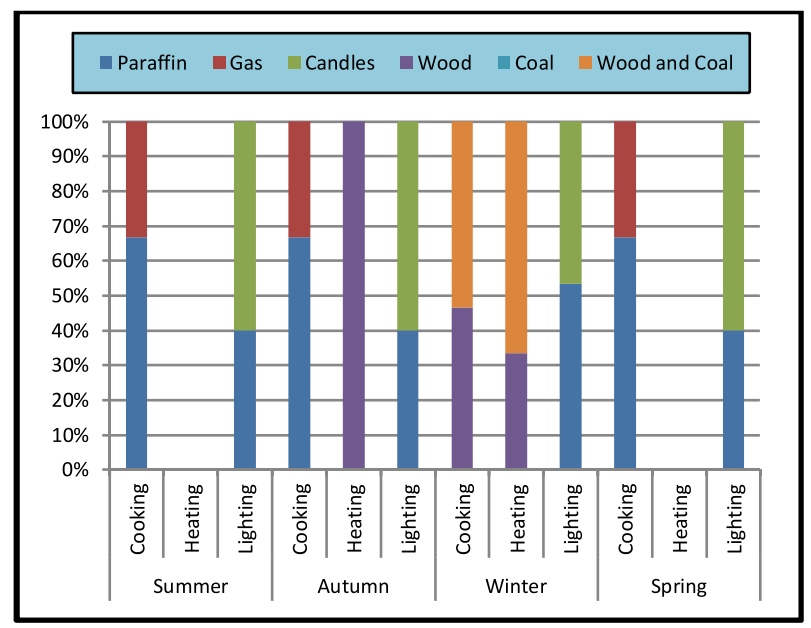

Figure 2. Percentages of the different fuel sources consumed by households

Most households, however, will change to other solid fuels, such as coal and wood during winter as larger quantities of energy are required for heating purposes. It is, however, very rare that these households will consume just coal. Coal is generally burnt simultaneously with wood. Reasons relating to both temperature and cost will prompt people to shift to these fuel sources. These fuels tend to be relatively inexpensive when compared to the cost of electricity and, with the large quantities required mainly for heating purposes in winter; coal and wood become the more feasible options (Mdluli et al. 2010). If coal stoves are available, people choose to provide for both their cooking and heating needs by this means, otherwise hand-built stoves (figure 3 ) will also be used. Of the households in Zenzele, participating in the field study, $53 \%$ utilised these hand-made stove and $47 \%$ used the bigger coal stoves.

Imbaulas are also made use of in informal settlements for the combustion of residential solid fuels. These are generally hand-built stoves, constructed from a metal drum, with strategically placed holes to filter in air to aid in the combustion process (figure 4). Characteristically, imbaula stoves will differ depending on the number and size of these holes (Kimemia et al. 2011). As imbaulas are not fitted with chimneys, they are generally only used for heating and cooking purposes and, as such fires created in these devices have to be done so outside so as to limit 


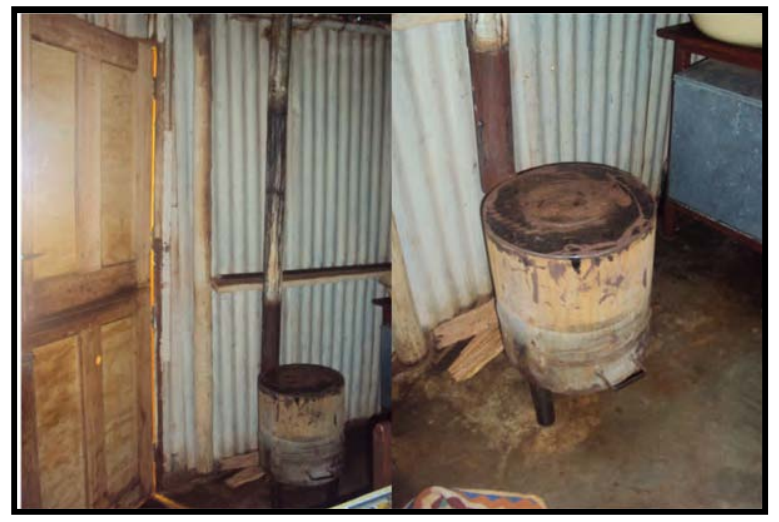

Figure 3. Photograph of hand-built stove

the amount of smoke circulating within households (Brauer et al. 1996).

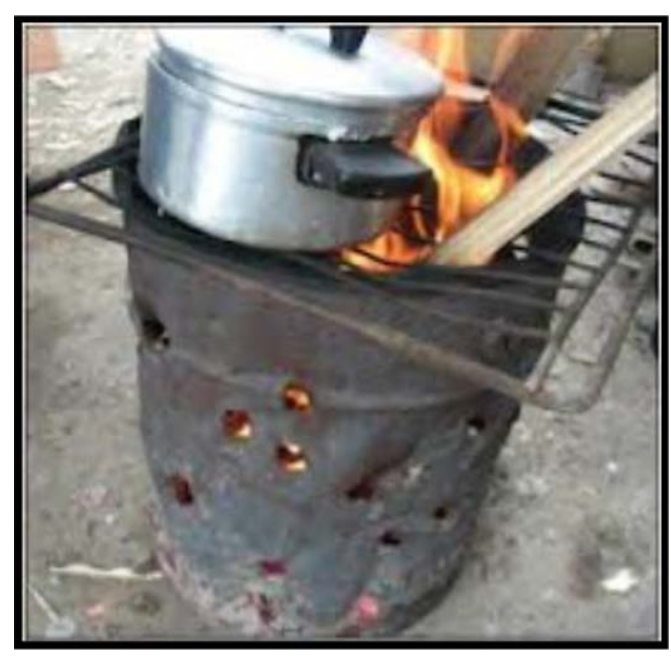

Figure 4. Imbaula stove (image from Kimemia et al. 2011)

\subsection{Scale Measurements}

The weights of both coal and wood consumed by each of the fifteen informal households were measured and then analysed, in order to obtain the average fuel consumption of the 15 households per day (figure 5). Total and average consumption rates calculated according to each household's recorded fuel use showed burning behaviours similar to those that were expected and brought to the fore after analysing the responses of the questionnaires.

The average amounts of wood and coal consumed per day during the morning and evening burning periods by the 15 households are illustrated in figure 5 . The bottom and top caps of the error bars represent the minimum and maximum average concentrations observed in that specific month, respectively. In most cases, an increase in the average consumption rates of both solid combustion fuels are seen during the colder months.

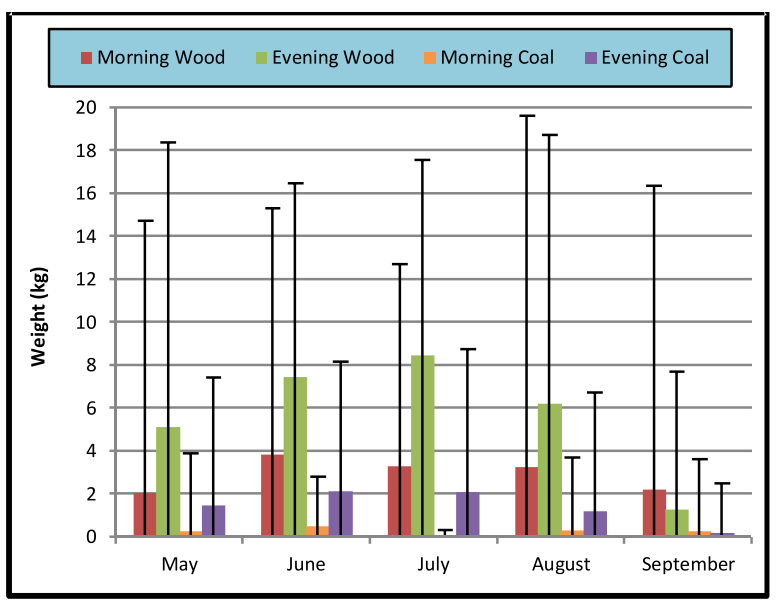

Figure 5. Average amounts of wood and coal consumed per day

The average amount of coal being consumed during this period for both the morning and evening burning sessions are on a far smaller scale to that of wood. Although wood is not as easily accessible in urban townships as it is in rural settlements, it is still cheaper than coal, if residents were to purchase fuelwood in times of scarcity. Relative to electricity, however, coal is cheaper and for this reason remains a common fuel source even in electrified households.

In addition figure 5 also highlights that larger amounts of both the fuel sources measured are consumed in the evenings. As most residents spend a limited amount of time in their homes in the morning before leaving for either school or work, the heat generated from a coal and/or wood fire would be wasted. For this reason, residents opt for other fuel sources that are more convenient to provide for their energy needs in the mornings. The heat produced from these fires can generally warm a home for hours after the fire has been lit.

A limited supply of either fuel source, wood or coal, would prompt residents to utilise these stocks during the evening burning sessions so as to gain the maximum benefit of the fire. Once the cooking has been done and the fire has progressed through all the combustion stages, evening fires are generally rekindled to provide additional heat for warmth throughout the night.

\subsection{Emission Estimates}

Figures 6 to 9 represent the average emission rates for all 15 households that correspond to the combustion of wood and coal during the morning and evening burning periods, for the four different pollutants under investigation. The emission factors associated with this set of pollutants are recorded on different scales and for this reason, although all the figures below apply the same base data, one graph will differ from the next. These emission estimates were calculated using a total burning period of 7 hours. It was assumed that the morning burning 
period lasts for 3 hours and the evening burning period lasts for 4 hours. The emission factors used for the combustion of wood and coal are as follows, in Table 1.

Table 1. Emission factors used to calculate emission estimates (adapted from the FRIDGE Report, 2004)

\begin{tabular}{|c|c|c|c|c|c|}
\hline & Units & $\mathrm{SO}_{2}$ & $\mathrm{PM}_{10}$ & $\mathrm{CO}_{2}$ & $\mathrm{CO}$ \\
\hline Coal & $\mathrm{g} / \mathrm{kg}$ & 19 & 4.1 & 2997.6 & 187.4 \\
\hline Wood & $\mathrm{g} / \mathrm{kg}$ & 0.18 & 15.7 & 1542.2 & 114.6 \\
\hline
\end{tabular}

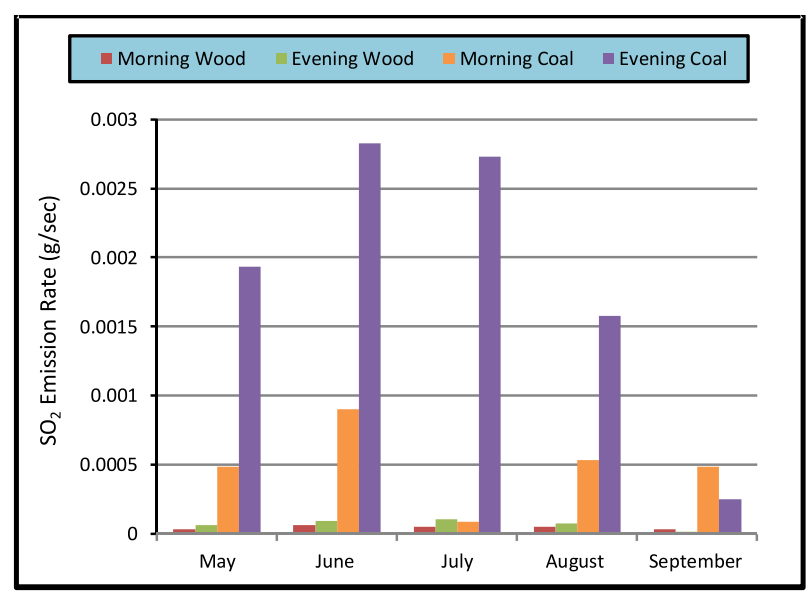

Figure6. Average $\mathrm{SO}_{2}$ emission rates per household

t has already been established and is evident in the consumption data that on average wood is consumed more frequently during both the morning and evening burning sessions. Figure 6 , however, illustrates $\mathrm{SO}_{2}$ emission rates for coal that are far higher than that of wood. This finding is contrary to what is expected as the higher emission rates should correspond to the fuel sources most frequently used. This may be attributed to the emission factors and the amount of sulphur dioxide released when coal is burnt as opposed to wood.

In figures 7, 8 and 9 where the emission rates from wood combustion are more pronounced, the seasonal trends associated with this type of combustion are evident. Generally the emission rates for both wood and coal are higher during the colder months.

The average emission rates for $\mathrm{PM}_{10}$ (figure 7), $\mathrm{CO}_{2}$ (figure 8) and $\mathrm{CO}$ (figure 9) show the highest values for the evening combustion of wood. These emission rates correspond with the large amounts of wood consumed over this study period. They also identify coal burnt in the mornings as having the

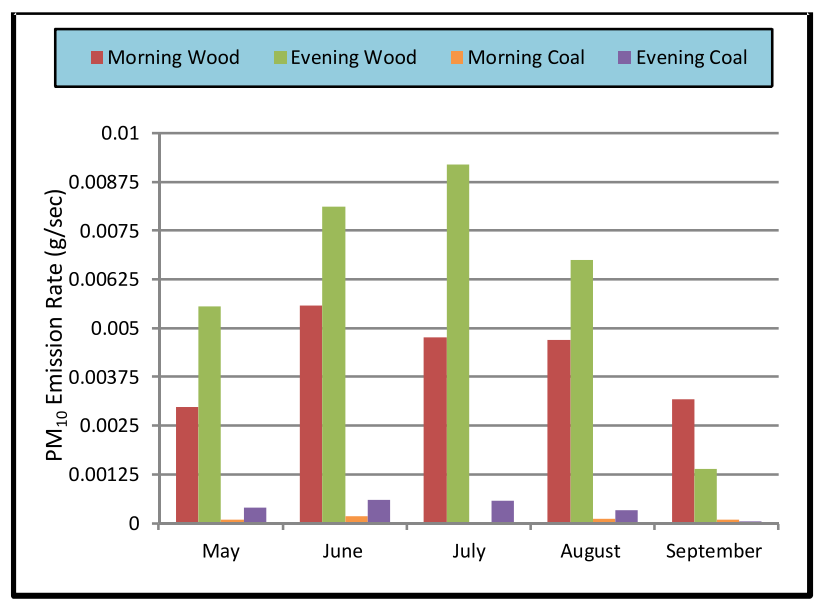

Figure 7. Average $\mathrm{PM}_{10}$ emission rates per household

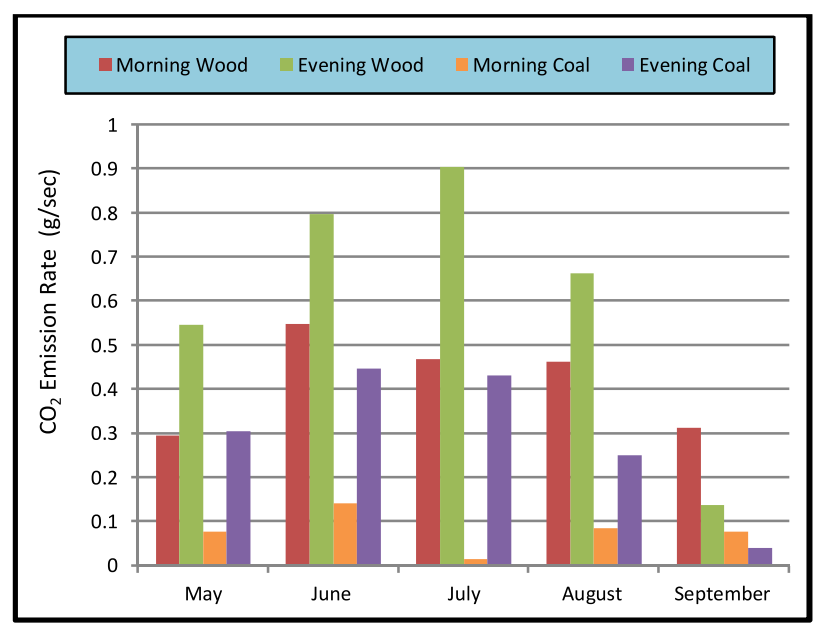

Figure8. Average $\mathrm{CO}_{2}$ emission rates per household

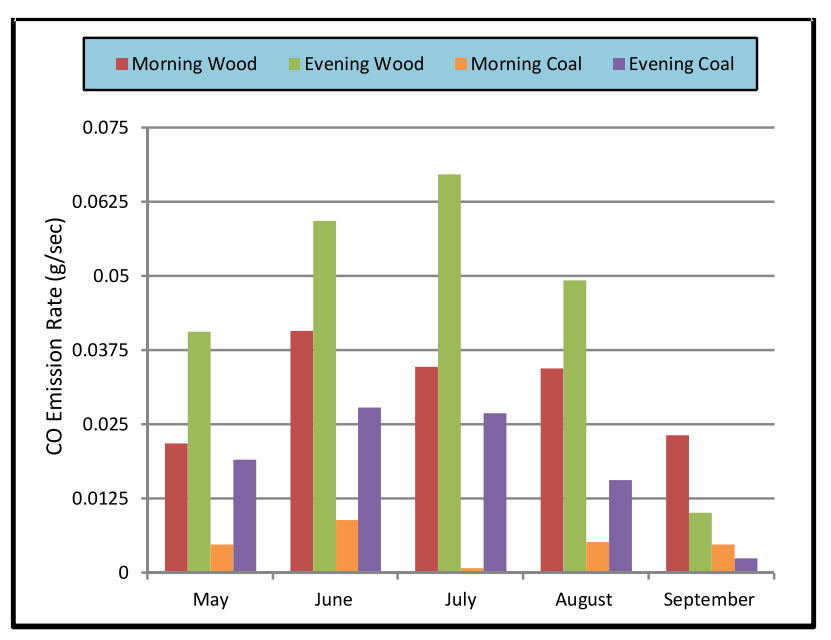

Figure 9. Average CO emission rates per household

lowest emission rates. This is in line with the expected trend as the consumption of coal during the morning burning sessions is far less than that consumed during the evening burning session. The lowest emission rates associated with the combustion of coal in the morning occurs in July. This pattern may 
be consistent with the increase in the price of coal during the colder months, as the demand for coal increases.

Residents opt for creating labour and fuel intensive fires in the evenings so as to gain the maximum benefit of the heat generated. In addition, coal is utilised more in the evenings in a bid to save already limited funds, as the demand for this commodity drives prices up (Mdluli et al. 2010). As a consequence of this increased demand, the supply and availability of both coal and wood can often also become a problem.

\section{Conclusion}

Faced with the options of fuel sources, Zenzele residents chose more than one fuel source, especially during winter. They further explained that wood was generally burnt in the mornings and that coal and wood were used in the evenings simultaneously (Davis 1998). In general the emission estimates for all the observed pollutants are higher during the colder winter months. They start to increase towards the end of May, and peak in July, followed by a gradual decrease during August and September.

Factors such as seasonality, the price and the availability of fuels as well as cultural aspects all have major influences on the fuel source type and the quantity consumed. From the above, it becomes clear that the most significant temporal observations identified for domestic burning are seasonal ones.

Often in a study such as this, there is uncertainty over the amounts of various fuel sources used in these areas, thereby making it difficult to estimate the amounts of fuel being burnt (Jones 1999). A large portion of this uncertainty lies in the lack of data surrounding the amount of fuel consumed and consequently the same uncertainty would apply to the emissions. This study sheds some light on the consumption of the common domestic fuel sources and their seasonal and temporal trends. It also provides a dataset on the consumption rates of some of these sources, and in so doing, attempts to address in some way the uncertainties associated with the consumption.

\section{References}

Adachi K. and Buseck P.R. 2008, 'Internally mixed soot, sulphates, and organic matter in aerosol particles from Mexico City', Atmospheric Chemistry and Physics Discussions 8:9179-9207.

Anderson B.E. Grant W.B. Gregory G.L. Browell E.V. Collins Jr J.E. Sachse G.W. Bagwell D.R. Hudgins C.H. Blake D.R. \& Blake N.J. 1996, 'Aerosols from biomass burning over the tropical South Atlantic region: Distributions and impacts', Journal of Geophysical Research 101(D19):24117-24137.
Aneja V.P. Agarwal A. Roelle P.A. Phillips S.B. Tong Q. Watkins N. \& Yablonsky R. 2001, 'Measurements and analysis of criteria pollutants in New Delhi, India', Environment International 27:35-42.

Balmer M. 2007, 'Household coal use in an urban township in South Africa', Journal of Energy in Southern Africa 18(3):27-32.

Bertschi I.T. Yokelson R.J. Ward D.E. Christian T.J. \& Hao W.M. 2003, 'Trace gas emissions from the production and use of domestic biofuels in Zambia measured by open-path Fourier transform infrared', Journal of Geophysical Research 108 (D13):84698482.

Boleji J.S.M. Ruigewaard P. \& Hoek F. 1989, 'Domestic Air Pollution from Biomass Burning in Kenya', Atmospheric Environment 23(8):1677-1681.

Brauer M. Bartlett K. Regalado-Pineda J. \& PerezPadilla R. 1996, 'Assessment of Particulate Concentrations from Domestic Biomass Combustion in Rural Mexico', Environment, Science \& Technology 30:104-109

Crutzen P.J. and Andreae M.O. 1990, 'Biomass Burning in the Tropics: Impact on Atmospheric Chemistry and Biogeochemical Cycles', Science 250:1669-1678.

Davis M. 1998, 'Rural household energy consumption: The effects of access to electricity evidence from South Africa', Energy Policy 26(3):207217.

Jones A.P. 1999, 'Indoor air quality and health', Atmospheric Environment 33:4535-4564.

Kimemia D. and Annegarn H. 2011, 'An urban biomass energy economy in Johannesburg, South Africa', Energy for Sustainable Development 15(4):382-387.

Ludwig J. Marufu L.T. Huber B. Andreae M.O. \& Helas G. 2003, 'Domestic Combustion of Biomass Fuels in Developing Countries: A Major Source of Atmospheric Pollutants', Journal of Atmospheric Chemistry 44:23-37.

Mdluli T.N. 2007, 'The Societal Dimensions of Domestic Coal Combustion: People's Perceptions and Indoor Aerosol Monitoring', Unpublished PhD Thesis, University of the Witwatersrand, Johannesburg.

Mdluli T.N. and Vogel C.H. 2010, 'Challenges to achieving a successful transition to a low carbon economy in South Africa: examples from poor urban communities', Mitigation and Adaptation Strategies for Global Change 15:205-222.

Muller E. Diab R.D. Binedell M. \& Hounsome R. 2003, 'Health risk assessment of kerosene usage in an informal settlement in Durban, South Africa', Atmospheric Environment, 37:2015-2022. 
Randfontein Local Municipality (RLM) 2010, '2010/11 IDP (Integrated Development Plan)'

ht t p: //www.randfontein.gov.za/wpcontent/themes/randfontein/docs/idp1011.pdf

Website accessed: November 2011.

Scorgie Y. Kneen M.A. Annegarn H.J. \& Burger L.W. 2003, 'Air Pollution in the Vaal Triangle - Quantifying Source Contributions and Identifying Cost-effective Solutions', Proceedings of the National Conference of the National Association of Clean Air (NACA), October 2003.

Stats SA (Statistics South Africa) 2011, 'Census 2011 Products'

http://www.statssa.gov.za/Census2011/Products/P rovinces\%20at\%20a\%20glance\%2016\%20Nov\%202 012\%20corrected.pdf Website accessed: August 2013.

Trade and Industry Chamber 2004, 'Funds for Research into Industrial Development Growth and Equity (FRIDGE), Study to examine the potential socio-economic impact of measures to reduce air pollution from combustion', Final Report.

Wentzel M. Gorzawski H. Naumann K.H. Saathoff H. \& Weinbruch S. 2003, 'Transmission electron microscopical and aerosol dynamical characterisation of soot aerosols', Aerosol Science 34:1347-1370. 